\title{
Haupt- und Sekundärinsolvenzverfahren
}

\author{
Zur sachgerechten Verfahrenskoordination bei grenzüberschreitenden \\ Unternehmensinsolvenzen
}

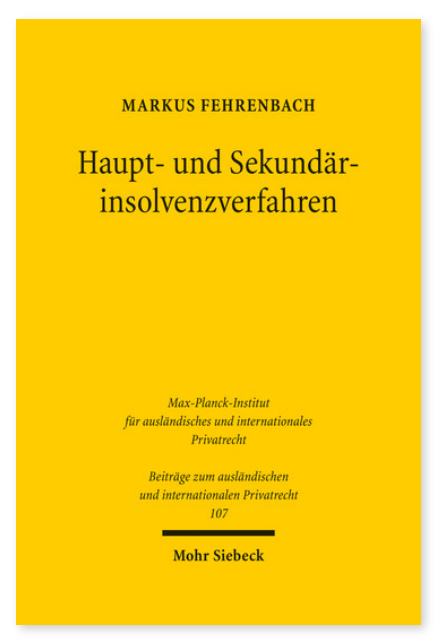

2014. XXXV, 549 Seiten. BtrIPR 107

ISBN 978-3-16-153504-8

DOI 10.1628/978-3-16-153504-8

eBook PDF 119,00€

ISBN 978-3-16-153476-8

Leinen $119,00 €$
Der Europäischen Insolvenzverordnung liegt ein Modell potentieller Verfahrenspluralität zugrunde, nach dem der grenzüberschreitende Insolvenzfall durch Haupt- und Sekundärinsolvenzverfahren bewältigt werden soll. Vor dem Hintergrund fortbestehender Unterschiede in den nationalen Rechtssystemen im Spannungsfeld zwischen effizienter Verfahrensabwicklung und effektivem Gläubigerschutz entwickelt Markus Fehrenbach ein System, das universale und territoriale Elemente vereinigt und dazu geeignet ist, den grenzüberschreitenden Insolvenzfall interessengerecht zu bewältigen. Er klärt die Struktur von Haupt- und Sekundärinsolvenzverfahren als Spaltprodukte eines ursprünglich universalen Gesamtverfahrens sowie ihr Verhältnis zueinander und ihr Zusammenwirken bei Liquidation und Sanierung.

Markus Fehrenbach Geboren 1975; Studium der Rechtswissenschaften in Passau und Toledo; 2011 Promotion; 2012 Habilitation; Lehrstuhlvertretungen an den Universitäten Mainz, Heidelberg, Halle-Wittenberg und Göttingen.

Jetzt bestellen:

https://mohrsiebeck.com/buch/haupt-und-sekundaerinsolvenzverfahren-9783161535048?no_cache=1

order@mohrsiebeck.com

Telefon: +49 (0)7071-923-17

Telefax: +49(0)7071-51104 